\title{
Enhancement corrosion resistance of (3-methacryloxypropyl)silsesquioxane hybrid films and its validation by gas-molecule diffusion coefficients using MD simulation
}

Di Wang $\cdot$ Xiaodong Chen $\cdot$ Xingwen Zhang $\cdot$

Yu Liu $\cdot$ Lijiang Hu

Published online: 25 August 2009

(C) Springer Science+Business Media, LLC 2009

Erratum to: J Sol-Gel Sci Technol

(2009) 49:293-300

DOI: $10.1007 / \mathrm{s} 10971-008-1871-4$

The original version of this article unfortunately contained a mistake in the author's address.
"Material Science and Engineering College, Northeast Forestry University, Harbin 150040, China". The correct address is Northeast Forestry University.

The online version of the original article can be found under doi:10.1007/s10971-008-1871-4.

D. Wang $\cdot$ X. Zhang $\cdot$ Y. Liu $\cdot$ L. Hu ( $($ )

Department of Applied Chemistry, Harbin Institute

of Technology, Box 713, 150001 Harbin, China

e-mail: hulijiang@vip.sina.com

\section{Wang}

Material Science and Engineering College, Northeast Forestry

University, 150040 Harbin, China

\section{Chen}

School of Economics and Management, Harbin Institute

of Technology, 150001 Harbin, China 